\title{
ESTIMATION OF LENGTH OF A FEMUR FROM THE LENGTH OF ITS FRAGMENTS
}

Sarzoo Girishbhai Desai ${ }^{1}$

\section{HOW TO CITE THIS ARTICLE:}

Sarzoo Girishbhai Desai. "Estimation of length of a femur from the length of its fragments". Journal of Evolution of Medical and Dental Sciences 2013; Vol2, Issue 29, July 22; Page: 5450-5457.

ABSTRACT: INTRODUCTION: Estimation of stature from bones has anthropological and forensic importance. The bones of the lower extremity namely the femur and tibia have yielded consistent and good results. Availability of long bone (without intact ends) is indeed a serious problem of stature estimation. This can be overcome by applying the method to the available fragment of bone. This will help to solve medico-legal problems giving due consideration to regional factors. AIM: The present study was designed to examine the correlation between total length of femur and the length of its fragments in dry bones to estimate stature. MATERIAL AND METHODS: Two hundred adult femora belonging to unknown age, sex and stature were studied. Total length and upper end lengths of femur were measured to fractions of a centimeter. Femur was divided into four segments with the help of salient bony points. Segment $A B$ from most proximal end of femur to most distal point of the circumference of the head. Segment BC from most distal point of the circumference of the head to lower border of lesser trochanter. Segment CD from lower border of lesser trochanter to adductor tubercle. Segment DE from adductor tubercle to lower margin of lower end of femur. RESULTS: Various measurements like mean, standard deviation and coefficient of variation were calculated. Average proportions of each segment to that of total length of the bone was determined. The percentage of bones lying within the range of \pm 2.5 S.D. have been determined to find out degree of significance of each proportion. CONCLUSION: Among the different segments, it is seen that significance was highest with the longest segment as compared to shortest segments.

KEY WORDS: Length of femur, fragmentary femur.

INTRODUCTION: Estimation of stature from skeletal remains has great importance in Forensic Medicine. Under such circumstances, it is necessary in the instance to make an estimate as possible of the probable length of the bone from such a fragment and then employ it in statural formulae. Owing to the medico-legal importance and significance, the proportions of various segments of the femur to its total length have been worked out.

MATERIAL AND METHODS: Two hundred ossified femora from Gujarat population were used in this study. 200 femora were studied from Anatomy Department of Smt N.H.L. Municipal Medical College, Ahmedabad. Out of 200 femora, 123 were of right side and 77 were of left side. Length of different fragments of femora and total length of the femora were measured on osteometric board.

Each bone was positioned in such a way that the highest point of the head was in contact with the fixed arm (i.e. vertical wall) of the board. The longitudinal axis of the bone was kept parallel to longitudinal axis of osteometric board. The movable arm was then brought into firm contact with the distal point on lower end of femur. A pointer with the edge perpendicular to the scale was moved on the vertical scale. The pointer was then fixed at bony point and distance between two points measured. (Fig. A) 


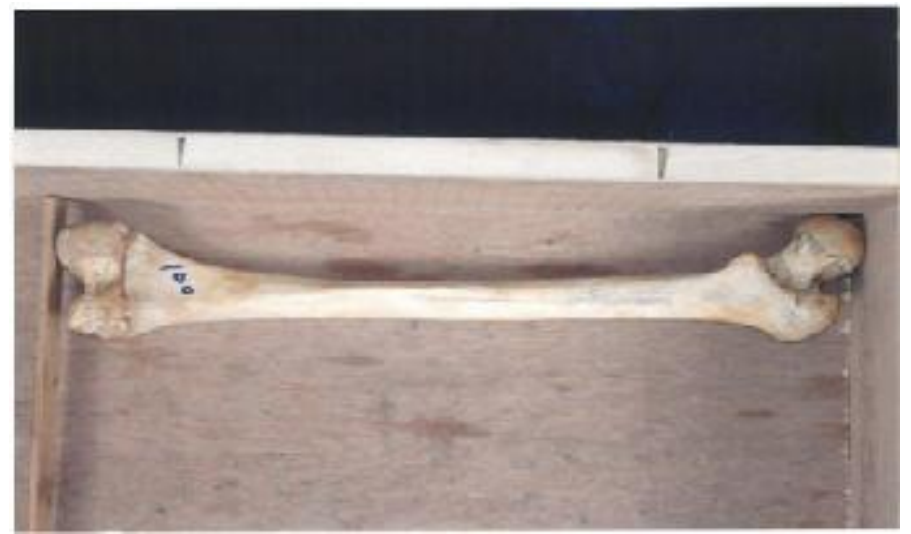

Fig. A Showing measurement of total length of femur on Osteometric board.

Following segments of bone were measured (Fig.1).

Segment AB: From Most proximal point on upper end of femur to most distal point of the circumference of the head of femur.

Segment BC: From most distal point of the circumference of the head of femur to lower border of lesser trochanter.

Segment CD: From lower border of lesser trochanter to adductor tubercle.

Segment DE: From adductor tubercle to most distal point on lower end of femur.

The observations were recorded and analysed. The ranges, arithmetic means, standard deviations and coefficient of variation for each segment and total length were calculated. 


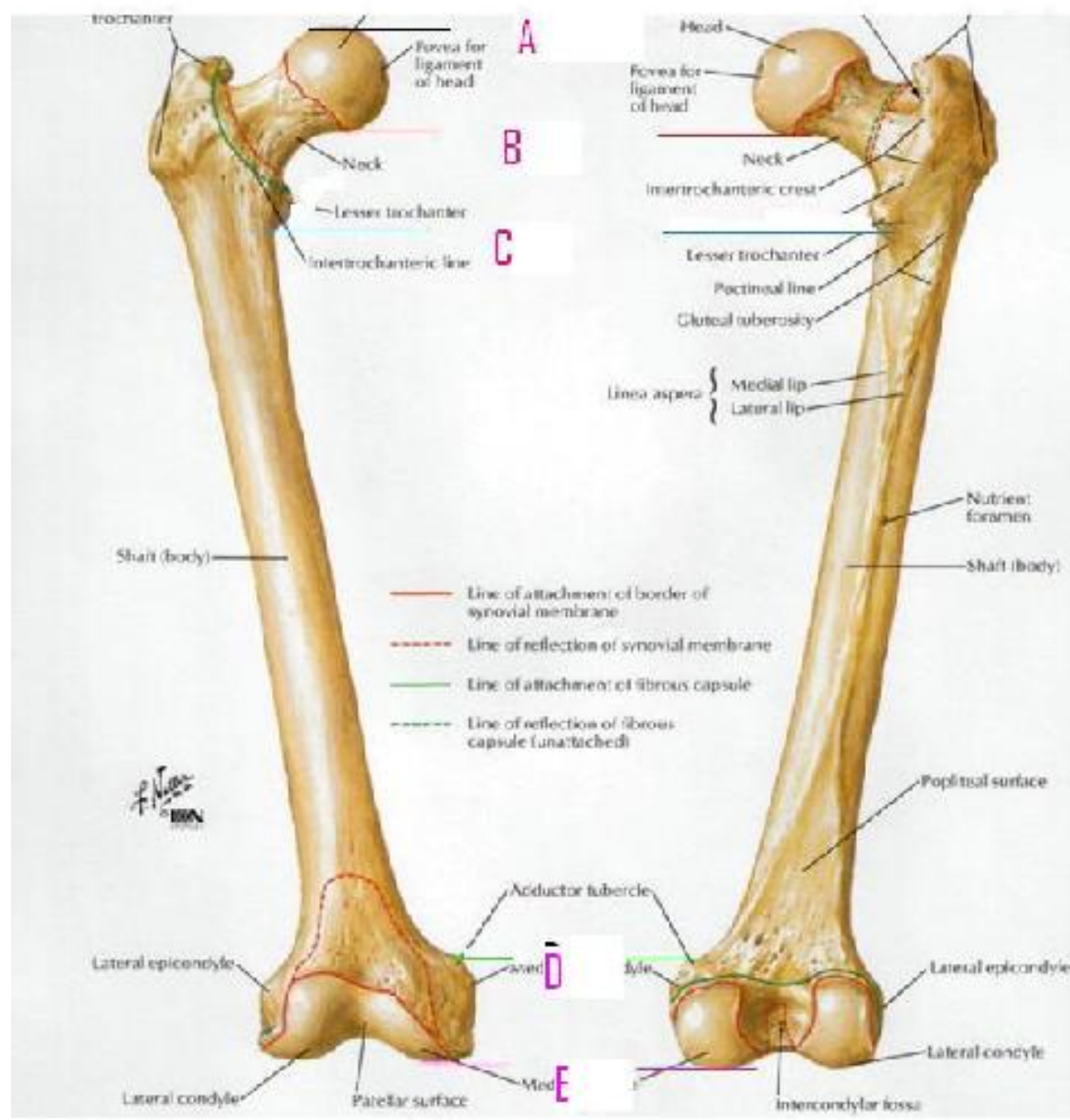

Fig.1: The landmarks used for demarcating the segments of the femur.
A: Most proximal point on upper end of femur
B: Most distal point of the circumference of the head of femur
C: Lower border of lesser trochanter
D: Adductor tubercle
E: Most distal point on lower end of femur.

OBSERVATIONS AND RESULTS: Table 1 show mean, standard deviation, coefficient variation and range of various segments of femur.

Table 1 showing various findings of different segments

\begin{tabular}{|c|c|c|c|c|}
\hline Segments & Mean $(\mathrm{cms})$ & S.D. & C.V. (\%) & Range $(\mathrm{cms})$ \\
\hline $\mathrm{AE}$ & 43.71 & 2.80 & 6.40 & $37.25-50.00$ \\
\hline $\mathrm{AB}$ & 4.12 & 1.49 & 3.62 & $3.20-5.15$ \\
\hline $\mathrm{BC}$ & 2.34 & 0.51 & 21.80 & $0.22-3.80$ \\
\hline $\mathrm{CD}$ & 32.66 & 2.17 & 6.64 & $37.75-39.20$ \\
\hline $\mathrm{DE}$ & 4.18 & 0.30 & 7.18 & $2.90-5.00$ \\
\hline
\end{tabular}

S.D. $=$ Standard deviation

C.V. = Coefficient of variation 
Table 2 shows proportions and significance of various segments.

\begin{tabular}{|c|c|c|}
\hline Segments & Proportions & Significance (\%) \\
\hline $\mathrm{AB}$ & 9.43 & 75.50 \\
\hline $\mathrm{BC}$ & 5.35 & 77.00 \\
\hline $\mathrm{CD}$ & 74.72 & 94.50 \\
\hline $\mathrm{DE}$ & 9.56 & 82.00 \\
\hline
\end{tabular}

Fig.2 Showing maximum length of femur AE in cms

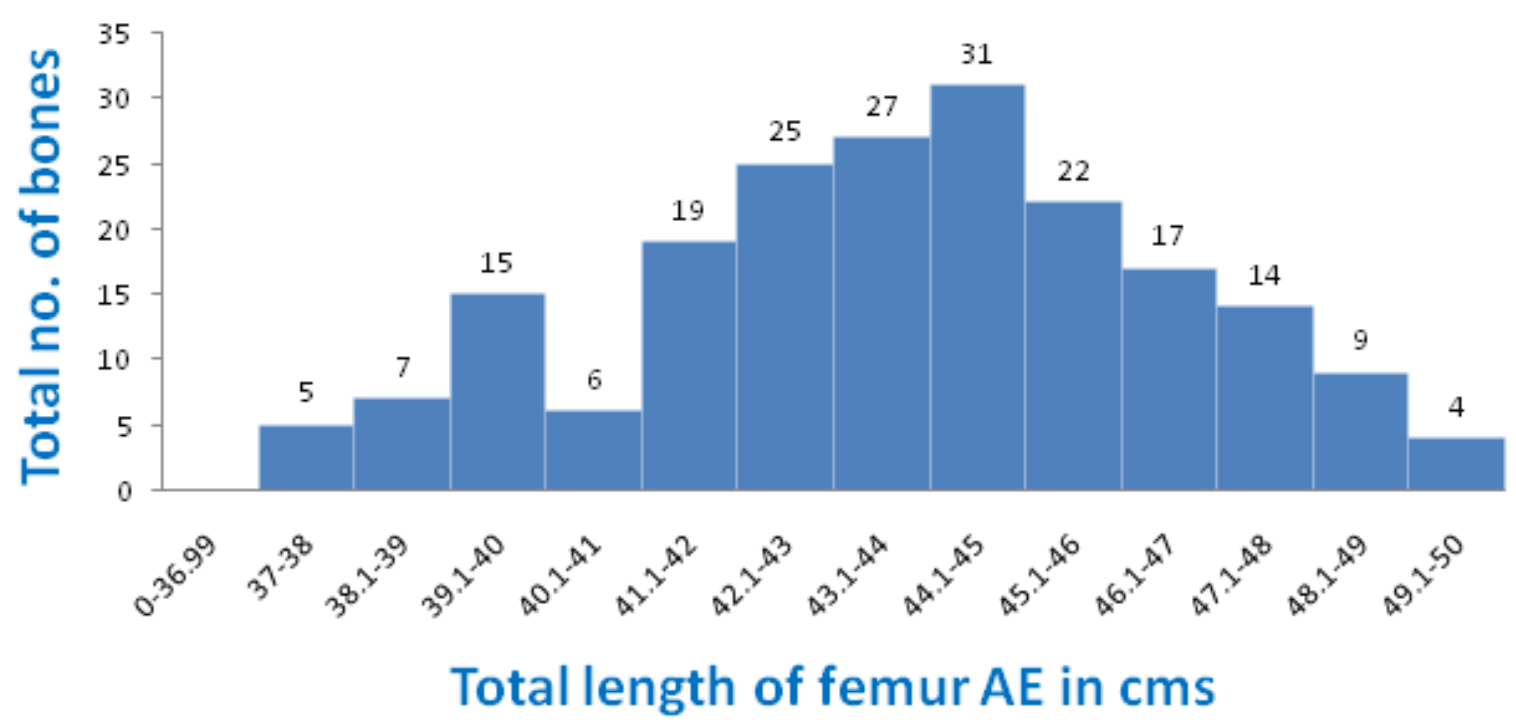

Fig.3 Showing distribution of segment $A B$ according to its length

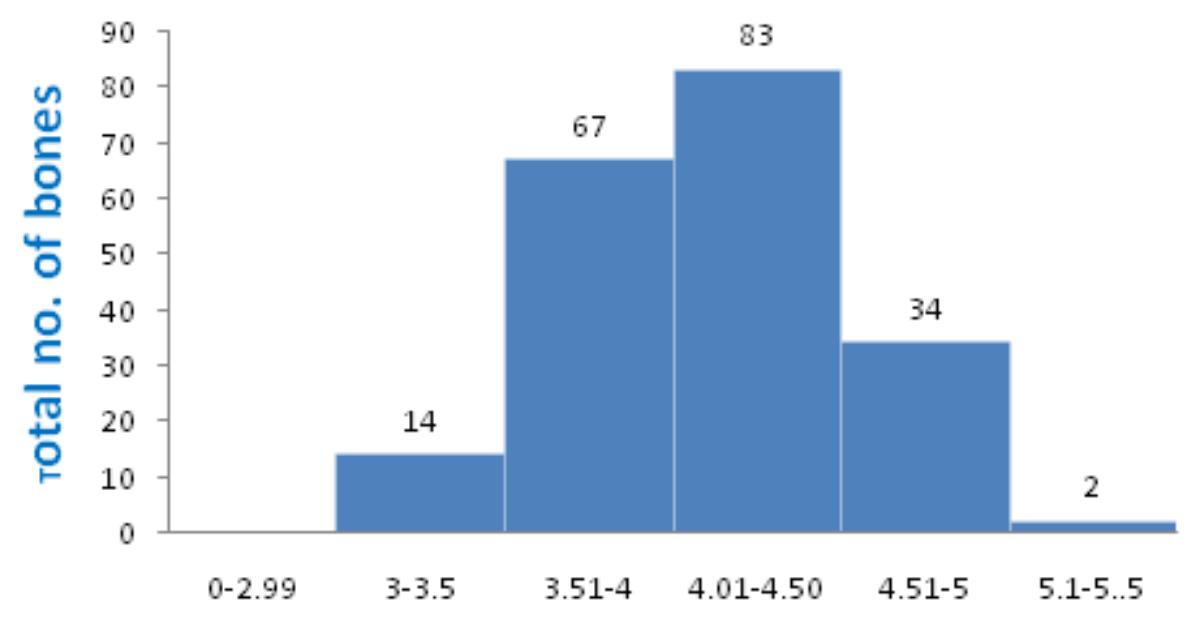

Length of $A B$ segment in $\mathrm{cms}$ 
Fig.4 Showing distribution of segment of BC according to its length

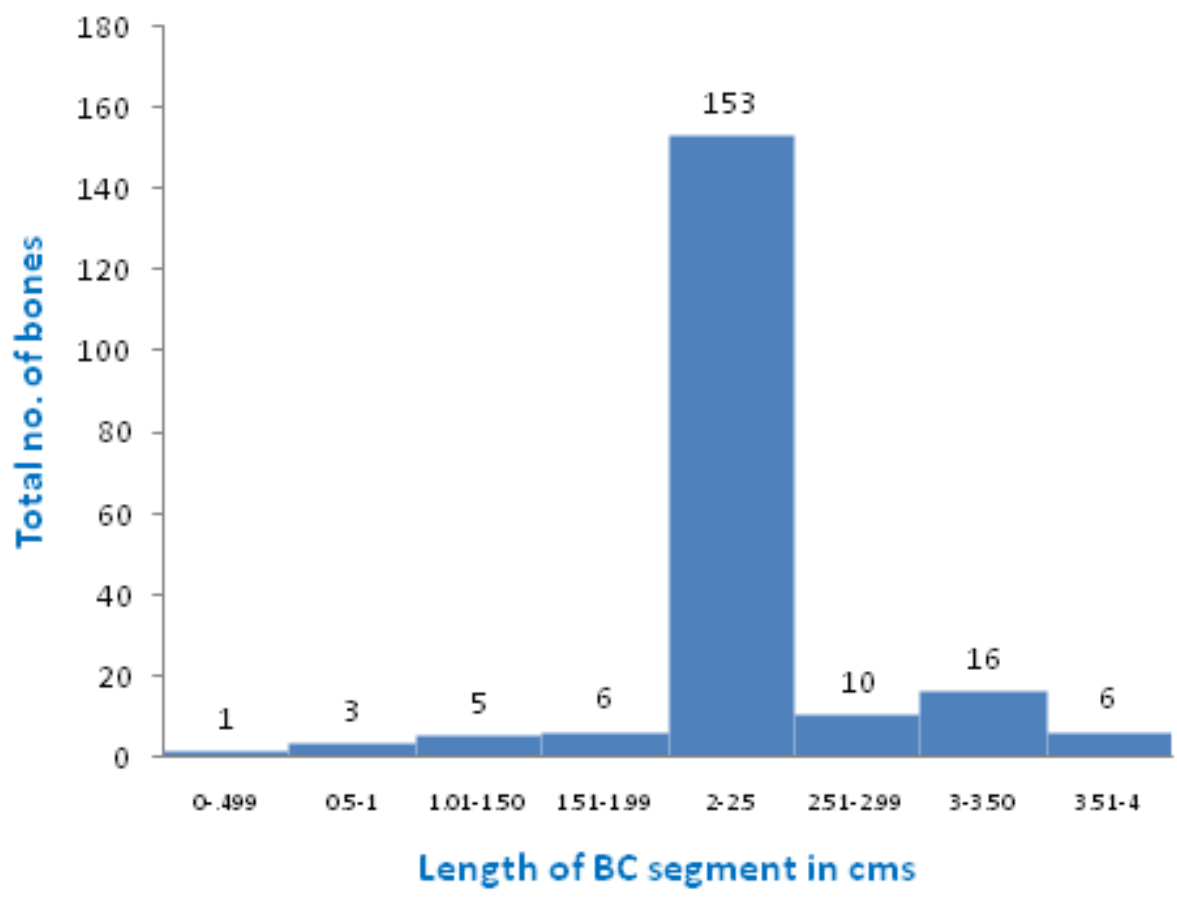

Fig.5 Showing distribution of segment DE according to its length

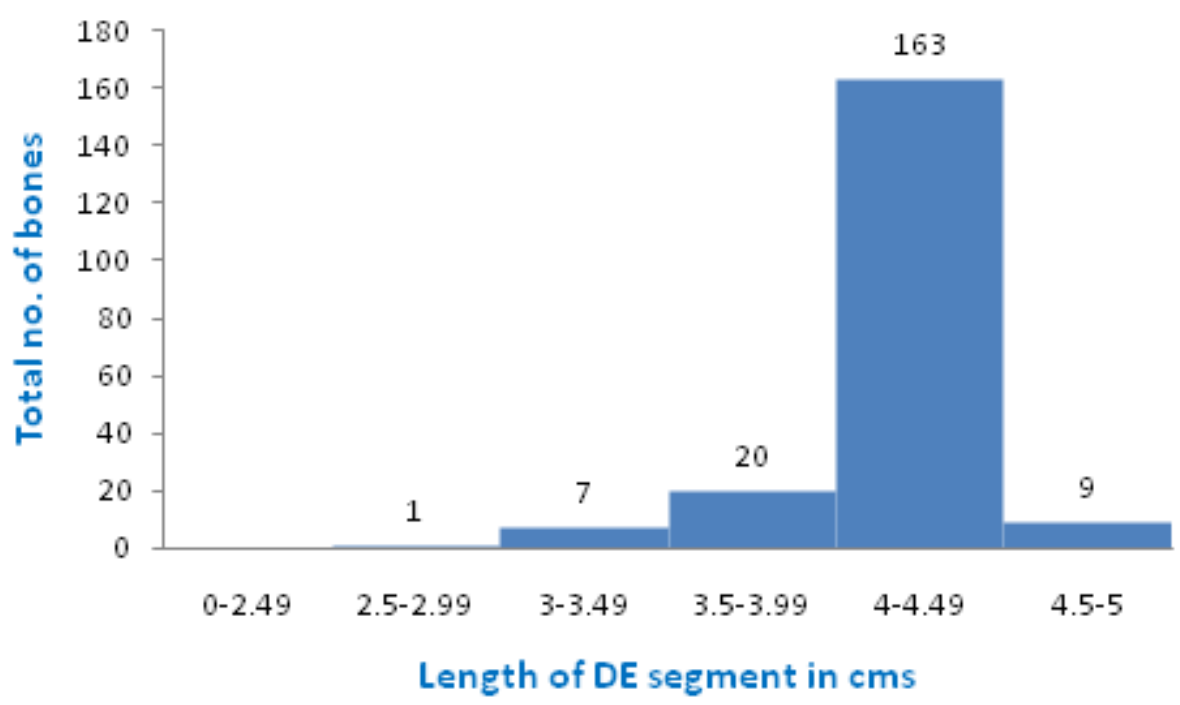


Fig.6 Showing distribution of segment CD according to its length

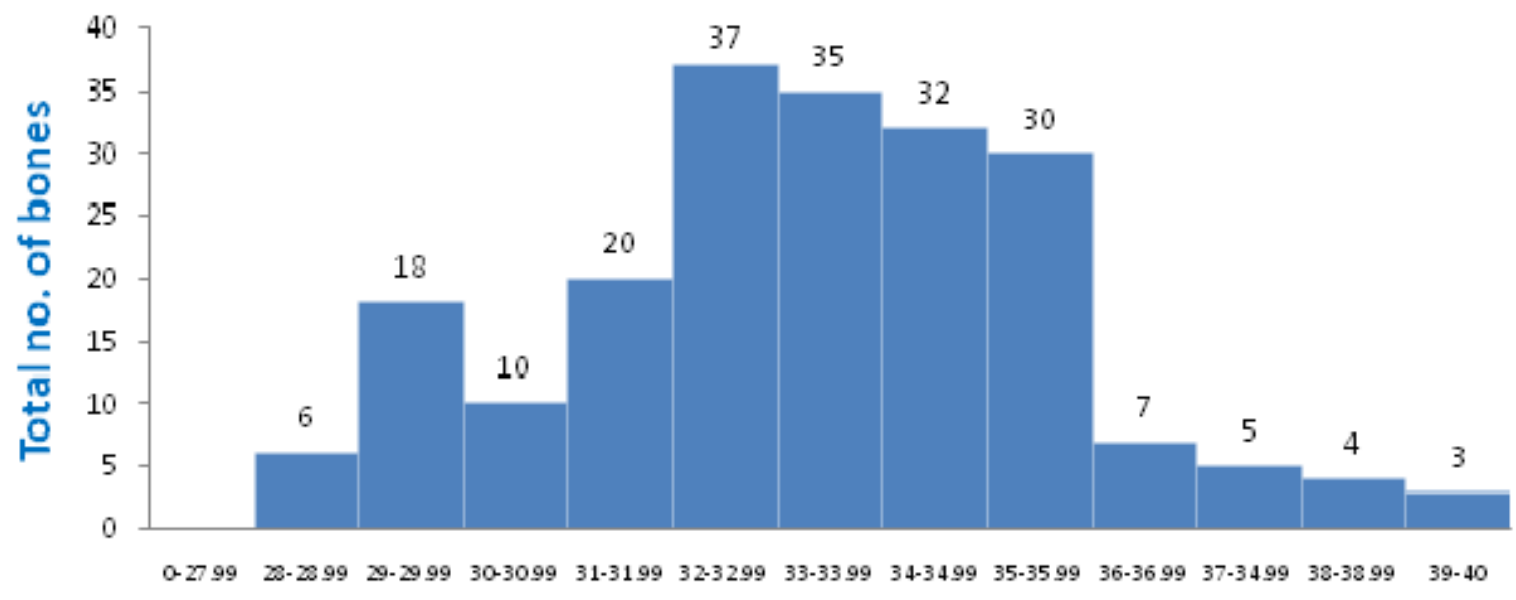

\section{Length of $C D$ segment in $\mathrm{cms}$}

It is apparent that mean total length of the femur (AE) is $43.71 \mathrm{cms}$ when 200 bones are taken for study. But the length of these bones is widely scattered within the range of $37.25-50$ cms (Fig.2) and standard deviation of 2.80 and coefficient of variation $6.40 \%$.

The mean value of the segment $A B$ has come out to be $4.12 \mathrm{cms}$ which is $9.43 \%$ of the total length of the bone. But the variation in the segment $A B$ is comparatively less with the range of $3.20 \mathrm{cms}$ to $5.15 \mathrm{cms}$ (Fig. 3) and standard deviation of 1.49 and C.V. 3.62\%. The proportion of the probable total length of the femur so calculated to be lying within the range of \pm 2.5 S.D. is $75.50 \%$.

The segment $\mathrm{BC}$ is the smallest with average length $2.34 \mathrm{cms}$, range $0.22-3.80 \mathrm{cms}$ (Fig.4) and S.D. 0.51. This segment is $5.35 \%$ of the total length of the bone. In this case 77.00 of the bones are laying within the range of \pm 2.5 S.D.

The segment $\mathrm{CD}$ is the longest segment of the bone with mean length $32.66 \mathrm{cms}$ which is $74.72 \%$ of the total length of the bone. The variation is also maximum in this segment (Fig. 6) with S.D. 2.17 and C.V. 6.64\%. In this segment nearly $94.50 \%$ of the bones are laying within the range of \pm 2.5 S.D.

The segment DE is scattered within the range of 2.90 to $5.00 \mathrm{cms}$ as shown in Fig. 5. The mean length of the segment is $4.18 \mathrm{cms}$ with S.D. 0.30 and C.V. $7.18 \%$. In this segment nearly $82 \%$ of the bones are laying within the range of \pm 2.5 S.D.

DISCUSSION: Muller (1935) [7] appears to be only worker who has studied the mean proportions of various parts of some long bones e.g. tibiae, humerii and radii to their total length. Muller [7] has not considered femur in his study on segmental bones because in his opinion femur has a wide variation in joint angles.

The estimation of stature from length of long bone has been reported by many workers (Trotter and Gloser, 1958 [11], Athawala, 1963 [1]). The linear regression equations to calculate stature from length of bones have been cited in 'Human Skeleton in Forensic Medicine' (Krogman, 1962) [5]. A successful reconstruction of the total length of the humerus and femur from available fragments of the bones has been reported in a case by Gorden and Drennan (1948) [4]. Bidmos (2008) [2] used six variables measured on each femur that included the vertical neck diameter, upper breadth of femur, epicondylar breadth, bicondylar breadth, lateral condyle length, and medial condyle length. Regression equations for the estimation of stature 
were presented. The range of standard error of estimate for these equations was slightly higher than those obtained for intact long bones. The said study suggested that in the absence of intact femur, regression equations could provide a reliable estimate of adult stature.

Shrof et al calculated (1999) [9] the percentile length of each segment and compared to total length. The regression equations were calculated to estimate total length of femur from its segments. They observed that regression coefficient in each case was highly significant. The length of femur was estimated by the equation was fairly accurate with a possible error of 0.5 to $1 \mathrm{~cm}$. Height could be calculated with the help of a small fragment of femur.

Steels and McKern (1969) [10] who calculated the percentile length of various fragments of femur and also regression equations to estimate the total length from the fragmentary length of femur. Steels and McKern [10] conducted a study on 72 male and 36 female femora collected from North Eastern Arkansas. They divided the femur in 5 segments with the help of following bony points: (1) The most proximal point of the head of the femur; (2) The mid-point of the lesser trochanter; (3) The most proximal extension of the popliteal surface at the point where the medial and lateral supracondylar lines become parallel below the lineal aspera; (4) The most proximal point of the intercondylar fossa; and (5) The most distal point of the medial condyle. Steels and McKern had taken second bony landmark at midpoint of lesser trochanter, while in present study second bony landmark taken at the most distal point of the circumference of the head of femur. Genoves (1967) [3] has analysed the combined sample of bones from right and left sides of the body, stating that the difference between the two bones from same individual were not significant.

The estimation of CR length form diaphyseal length of femur has been well studied (Mehta and Singh, 1972) [6]. Estimation of crown lump length from long bones of upper limb, humerus, ulna and radius (Vare and Atre, 1976) [12].Segmental lengths of some bones of Indian origin had been studied by Mysorekar (1980) [8].

CONCLUSIONS: Amongst the linear segments, it is seen that the significance reaches as high as $95 \%$ in case of long segment CD than in the case of short segment AB or BC (about $75 \%$ in each). It is, therefore, observed that the longer the segments of the bone, the better are the results.

It is concluded from this study that the proportions of this bone can be useful in calculating the approximate total length of the bone from the length of an unknown fragment in medico-legal cases. With the help of the statural formulae, the length so calculated may be used in determining the probable stature of a person in such cases.

\section{REFERENCES:}

1. Athawala, M.C. (1963). Estimation of height from length of forearm bones. A study of one hundred Maharashtrian male adults of ages between 25 and 35 years. American Journal of Physical Anthropology 21: 105-112.

2. Bidmos A Mubarak (2008). Stature reconstruction using fragmentary femora in South Africans of European descent. Journal of forensic sciences; 53 (5): 1044-1048.

3. Genoves, Sentiago (1967). Proportionality of the long bones and their relations to stature among Meso-Americans. American Journal of Physical Anthropology 26: 67-78.

4. Gorden, I. and Drennan, M. R. (1948). Medico legal aspect of the Wolkersdorfer case S. Afr. Med. J. 22, 543.

5. Krogman, W.M. In: The Human Skeleton in Forensic Medicine pp.179-180, Spring Field, Charis C. Thomas (1962). 
6. Mehta, L. and Singh, H.M. (1972). Determination of crown rump length from foetal long bones, humerus and femur. American Journal of Physical Anthropology 36: 165-168.

7. Muller G. (1935). Zur Bestemmung der Lange Beschadigter Extremitatenknochen. Anth. Anzeig. 12, 70-72, cited by Krogman, W. M. (1962). P.179. vide supra.

8. Mysorekar, V.R., Verma, P.K., Nandedkar, A.N. and Sarma, T.C.S.R. (1980). Estimation of stature from parts of bones-lower end of femur and upper end of radius. Medical Science and Law 20: 283-286.

9. Shroff A G, Panse A, A Diwan (1999). Estimation of length of femur from its fragments. Journal of Anatomical Society of India; 48(1): 42-49.

10. Steels, G.D. and McKern T.W. (1969). A method of assessment of maximum long bone length and living stature from fragmentary long bones. American Journal of Physical Anthropology 31: 215-228.

11. Trotter, M. and Gloser, G. G. (1958). A revaluation of estimation of stature based on measurements of stature taken during life and bones after birth. American Journal of Physical Anthropology. 16: 79-123.

12. Vare, A.M. and Atre, P.R. (1976). Estimation of crown lump length from long bones of upper limb, humerus, ulna and radius. Journal of J.J. Groups of Hospitals and Grant Medical College XXI: 3.

\section{AUTHORS:}

1. Sarzoo Girishbhai Desai

\section{PARTICULARS OF CONTRIBUTORS:}

1. Assistant Professor, Department of Anatomy, AMCMET Medical College, Maninagar, Ahmedabad.

\section{NAME ADRRESS EMAIL ID OF THE CORRESPONDING AUTHOR:}

Dr. Sarzoo G. Desai,

Anatomy Department, AMCMET Medical College, Ahmedabad.

Email-drdesaig@rediffmail.com

Date of Submission: 11/07/2013. Date of Peer Review: 12/07/2013. Date of Acceptance: 17/07/2013. Date of Publishing: 20/07/2013 